\title{
DIAGNÓSTICO E CARACTERIZAÇĀO DO REVESTIMENTO DAS FACHADAS DO ANEXO I DO CAMPUS DA SAÚDE DA UNIVERSIDADE FEDERAL DO RIO GRANDE DO SUL (UFRGS)
}

\author{
ZINI, ALINE \\ Mestranda em Engenharia \\ Universidade Federal do Rio Grande do Sul \\ Rio Grande do Sul; Brasil \\ zini.aline93@gmail.com
}

\author{
BIANCHETTI, LUIZ GUSTAVO MALLMANN \\ Mestrando em Engenharia \\ Universidade Federal do Rio Grande do Sul \\ Rio Grande do Sul; Brasil \\ mallmann.bianchetti@gmail.com
}

\author{
SOCOLOSKI, RAFAELA FALCÃO \\ Doutoranda em Engenharia \\ Universidade Federal do Rio Grande do Sul \\ Rio Grande do Sul; Brasil \\ rafaela_socoloski@hotmail.com
}

\author{
BERSCH, JÉSSICA DEISE \\ Mestranda em Engenharia \\ Universidade Federal do Rio Grande do Sul \\ Rio Grande do Sul; Brasil \\ jessicadbersch@gmail.com

\section{GUERRA, FERNANDA LAMEGO} \\ Pós doutoranda em Engenharia \\ Universidade Federal do Rio Grande do Sul \\ Rio Grande do Sul; Brasil \\ f.lamegoguerra@gmail.com \\ MASUERO, ANGELA BORGES \\ Doutora e Professora de Engenharia \\ Universidade Federal do Rio Grande do Sul \\ Rio Grande do Sul; Brasil \\ angela.masuero@ufrgs.br
}

\section{RESUMO}

Este trabalho apresenta o diagnóstico e a caracterização do revestimento fulget e de pastilha cerâmica das fachadas da edificação conhecida como Anexo I do Campus da Saúde da UFRGS, em Porto Alegre, RS. O diagnóstico foi realizado a partir do levantamento visual e mapeamento de danos, além de ensaios de percussão e termografia; os revestimentos foram caracterizados com base em ensaios laboratoriais de reconstituição de traço e teste qualitativo de sais solúveis. Dentre as manifestações patológicas identificadas, destacaram-se os descolamentos e os desplacamentos de revestimento, corroborados pelos ensaios de termografia e percussão. A reconstituição de traço permitiu a identificação da provável presença de agregado calcário no revestimento fulget. No emboço subjacente, o proporcionamento dos materiais variou entre 1:1,59 e 1:3,55 (ligante:agregado, em massa) em função da época de construção das diferentes partes do Anexo I; no chapisco, ficou em torno de 1:2,19. Foram identificados sais solúveis, tais como sulfatos e cloretos, nas fachadas mais recentes da edificação.

Palavras-chave: diagnóstico, caracterização, revestimento, cerâmica, fulget.

\section{ABSTRACT}

This work presents diagnosis and characterization of the fulget and ceramic coatings from the facades of the building known as Anexo I do Campus da Saúde of UFRGS, in Porto Alegre, RS. The diagnosis was done with visual survey and damages mapping, in addition to percussion and termography tests; the coatings were characterized with laboratory tests to determine the proportions binder:aggregate and the occurrence of soluble salts. Beyond the pathological manifestations identified, detachments and displacements were leading, which was corroborated by termography and percussion tests. The proportioning binder:aggregate allowed the identification of the probable occurrence of limestone aggregate on the fulget coating. The proportioning of the materials of the underlying plaster varied between 1:1,59 and 1:3,55 (binder:aggregate, in mass) according to the period of construction from the different parts of the Anexo I; for the roughcast, it was around 1:2,19. Soluble salts were identified, like sulfates and chlorides, on the more recent facades of the building.

Keywords: diagnosis, characterization, coating, ceramic, fulget. 


\section{INTRODUÇÃO}

As fachadas das edificações fazem parte da composição do ambiente em que se localizam, contribuindo, nesse sentido, para a sua qualidade. Caso se apresentem degradadas, por outro lado, poderão impactar negativamente em seu entorno,considerando-se não somente problemas de funcionalidade, mas também outros aspectos, uma vez que as edificações devem ser gerenciadas de pontos de vista técnicos, econômicos e sociais (FLORES-COLEN; BRITO, 2002).

Ao longo de sua vida útil, as fachadas das edificações estão sujeitas a um processo complexo de degradação. Esse processo envolve diversos fatores, cuja compreensão é imprescindível no sentido de controlar os seus efeitos e as possíveis manifestações patológicas deles resultantes. Dentre as manifestações patológicas, as fachadas podem apresentar problemas de natureza estética, de segurança, entre outros (MADUREIRA et al., 2017).

Nesse sentido, é de fundamental importância a realização de inspeções e diagnósticos referentes às fachadas, de forma a auxiliar na escolha de medidas adequadas de intervenção, na busca pela solução das manifestações patológicas, evitando seu agravamento e buscando o entendimento de suas causas (GONÇALVES; BRITO; AMARO, 2014). Inspecionar as edificações também se mostra necessário ao desenvolvimento de planos de manutenção para as fachadas, de forma a conduzir as ações de manutenção com eficiência em termos de recursos e de custos (MADUREIRA et al., 2017).

Pode-se destacar, portanto, a importância desse tipo de levantamento em termos de manutenção corretiva que, de acordo com Flores-Colen e Brito (2002), visa à correção de manifestações patológicas inesperadas e, por vezes, com caráter urgente. Em termos de manutenção preventiva, permite o planejamento de ações a serem tomadas e a consequente redução de trabalhos não planejados. Adiciona-se que a manutenção corretiva acaba, muitas vezes, sendo preventiva, já que uma manifestação patológica não tratada pode levar a outras mais agressivas, como por exemplo, uma fissura não selada permite o acesso da água que ao infiltrar pode levar a outras manifestações como eflorescências, perda de aderência entre outras.

Nesse contexto, o presente trabalho apresenta como objetivo o diagnóstico e a caracterização dos revestimentos de fachadas da edificação conhecida como Anexo I, localizada no Campus da Saúde da Universidade Federal do Rio Grande do Sul (UFRGS), na cidade de Porto Alegre, no estado brasileiro do Rio Grande do Sul (RS). Este artigo é baseado no trabalho de Zini et al. (2019), desenvolvido pela turma da disciplina de Patologia das Edificações, ministrada pela professora $\operatorname{Dr}^{\mathrm{a}}$ Angela Borges Masuero, no Núcleo Orientado para a Inovação da Edificação (NORIE), do Programa de Pós-Graduação em Engenharia Civil: Construção e Infraestrutura (PPGCI), da UFRGS.

\section{MATERIAIS E MÉTODOS}

\subsection{A edificação em estudo}

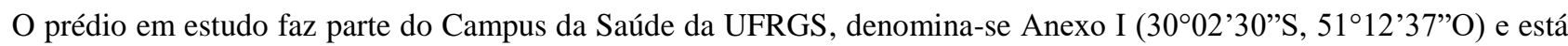
localizado conforme a figura 1 . O entorno da edificação é composto pelos demais prédios do próprio campus da universidade e por prédios residenciais. Além disso, o entorno é bastante arborizado e a localização da edificação é próxima de importantes vias do sistema de transporte da cidade, a Avenida Ipiranga e a rua Ramiro Barcelos. 


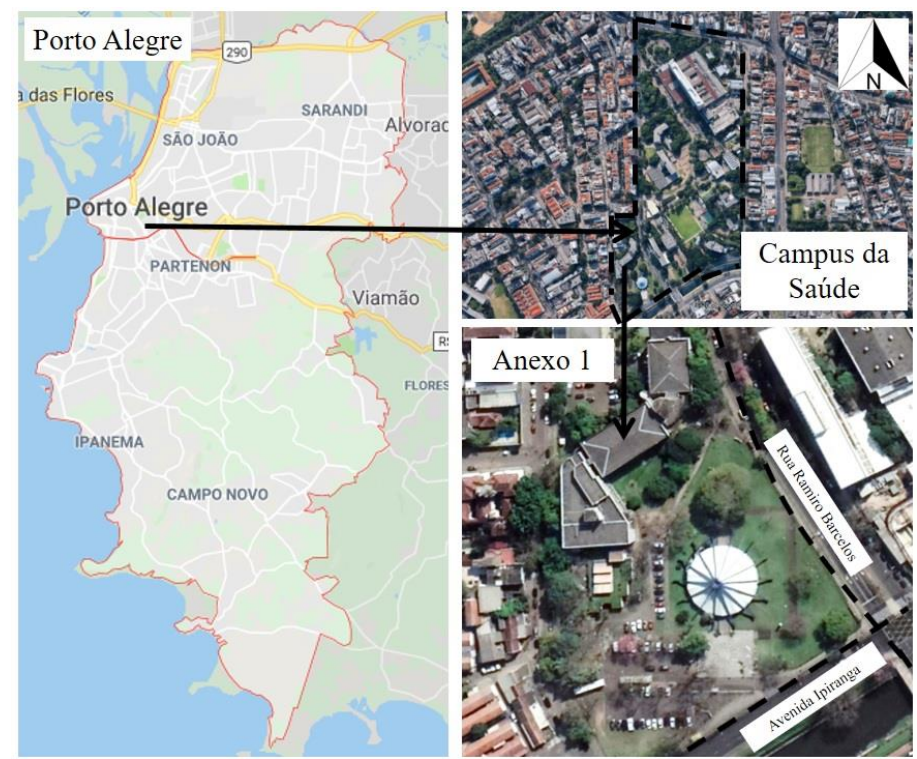

Figura 1: Localização do Campus da Saúde e do Anexo I na cidade de Porto Alegre (fonte: adaptado de Google Maps e Google Earth, 2019)

O clima é um dos agentes agressivos às edificações, assim, compreender a insidência solar, chuva dirigida e ventos do local colabora para o entendimento da origem das manifestações patológicas encontradas nas fachadas. A cidade de Porto Alegre apresenta temperatura média anual de $15,6^{\circ} \mathrm{C}$, variando entre uma média de $10,8^{\circ} \mathrm{C}$ no mês de junho e $20,7^{\circ} \mathrm{C}$ em fevereiro. A umidade relativa média anual é de $76 \%$, variando entre média de $71 \%$ no mês de dezembro e $82 \%$ em junho (WREGE et al., 2012).

Para Porto Alegre, a frequência de chuva dirigida é maior nas direções leste, leste-sudeste e sul, considerando-se a totalidade de horas de chuva (SILVA; GIRALT, 1995; KLEBER, 2018). Em relação à radiação solar, no inverno, a sua incidência ocorre especialmente nas fachadas voltadas para o norte; já no verão, as orientações leste e oeste são as que recebem maior incidência solar, sendo similar a incidência nas orientações norte e sul (MASCARÓ, 1991).

De acordo com informações do Setor de Patrimônio Histórico (SPH) da UFRGS, o Anexo I do Campus da Saúde foi projetado por arquitetos da UFRGS - Cirillo Crestani, Marcelo Spolaor e Ronaldo Kern Alvim. Foi inaugurado em 1994 para abrigar a Escola Técnica de Comércio da universidade, posteriormente denominada somente de Escola Técnica e que foi transformada no Instituto Federal do Rio Grande do Sul (IFRS) em 2008.

A partir do ano de 1999, foi realizada uma ampliação de $2700 \mathrm{~m}^{2}$ na edificação, distribuída em quatro pavimentos, consistindo em 20 laboratórios e salas de apoio (IFRS, 2019). A figura 2 apresenta a planta baixa do térreo da edificação, destacando a área acrescentada. Atualmente, a edificação abriga, principalmente, salas de aula, laboratórios e anfiteatro.

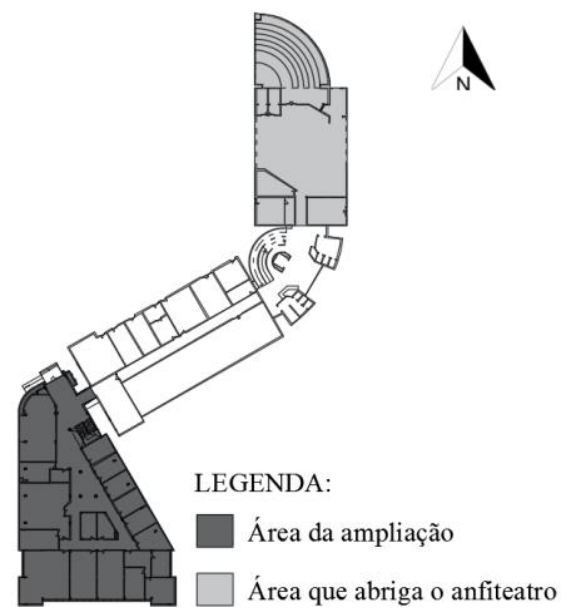

Figura 2: Planta baixa do térreo e área de ampliação da edificação, após 1999 (fonte: adaptado de SPH, 2019) 
A edificação apresenta três pavimentos, com exceção da área que abriga o anfiteatro, também destacado na figura 2 , com aproximadamente metade dessa altura. O revestimento das fachadas é composto por áreas com fulget, na cor acinzentada, e áreas com pastilhas cerâmicas em tons de verde escuro, azul e bege. A figura 3 ilustra a fachada principal da edificação, revestida com pastilhas cerâmicas, e uma de suas fachadas voltadas para o leste, contendo também revestimento em fulget.

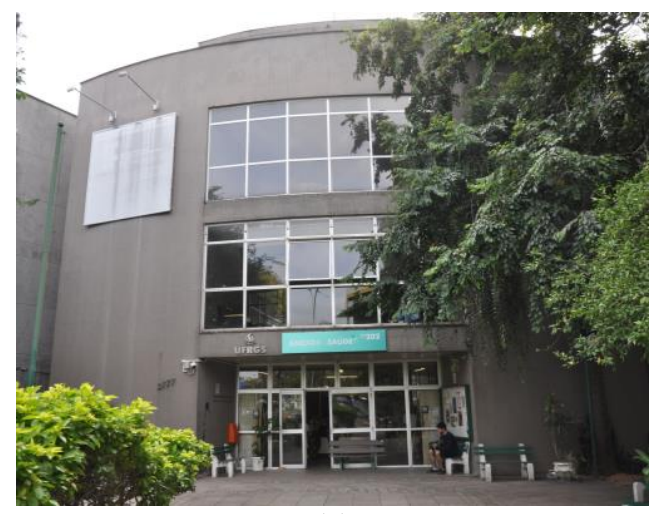

(a)

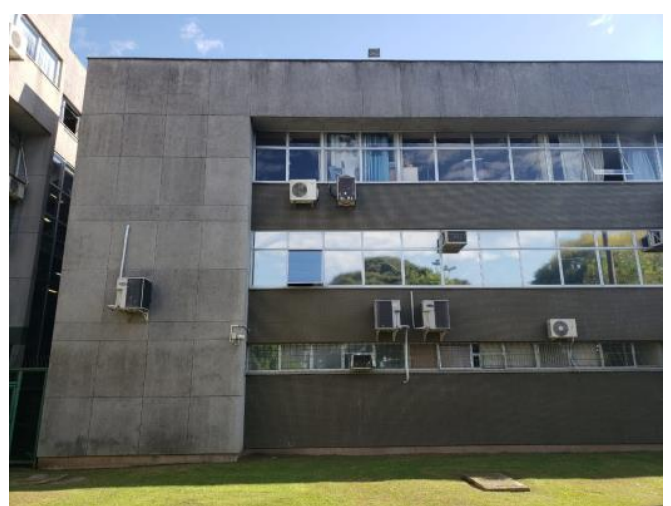

(b)

Figura 3: (a) Fachada principal da edificação revestida com pastilhas cerâmicas; (b) Fachada voltada para o leste com revestimento em fulget e pastilhas cerâmicas

\subsection{Levantamento das manifestações patológicas}

Para o levantamento das manifestações patológicas realizou-se a inspeção visual com mapeamento de danos, ensaio de percussão e termografia infravermelha.

\subsubsection{Levantamento visual e mapeamento de danos}

Buscando obter o máximo de informações acerca da edificação estudada, realizou-se a investigação documental da mesma. Nessa etapa, foram obtidos dados acerca da construção, tais quais: suas características arquitetônicas, as utilizações prévias do prédio, especificações e projeto do sistema de revestimento da fachada, sua idade e eventuais manutenções e reparos.

Na sequência, foi realizada a inspeção visual, etapa para a verificação do estado de conservação da edificação e da ocorrência de manifestações patológicas no revestimento de fachada, além das suas possíveis causas. Para tal, foram feitas visitas in loco para a investigação de detalhes construtivos, dos tipos de revestimento, de fatores de degradação e fatores externos que podem afetar o desempenho do sistema construtivo. As visitas foram realizadas no primeiro semestre do ano de 2019.

A fim de auxiliar a identificação dos danos, foi realizado o levantamento fotográfico das fachadas para a localização adequada de cada degradação. A utilização de imagens com boa resolução é uma etapa importante na inspeção, pois oferece suporte e esclarecimento para o reconhecimento e elucidação das anomalias e de suas causas (SILVA, 2014). A partir dos dados coletados, foram confeccionados mapas de danos para a sua localização na fachada com o auxílio do software gráfico AUTOCAD.

Para o mapeamento de danos, as seguintes manifestações patológicas foram investigadas no revestimento da edificação: biodeterioração; descolamento com ou sem possível desplacamento imediato; desplacamento; fissuras; manchamento por sujidade; manchamento por umidade; criptoflorescência de sais; eflorescência de sais; desgastes no revestimento; desgastes nas pastilhas e manchamento por corrosão.

\subsubsection{Ensaio de percussão}

O teste de percussão consiste na utilização de um martelo de plástico ou madeira para aplicar impactos leves sobre o revestimento com a finalidade de identificar problemas de aderência (COSTA, 2013). O descolamento no revestimento está correlacionado ao som cavo emitido. Este ensaio é o recomendado pela ABNT NBR 15575-4 (2013), que tolera área individual descolada que não ultrapasse os $0,10 \mathrm{~m}^{2}$ ou área total correspondente a $5 \%$ do pano de fachada. 
O limite de altura para o ensaio de percussão foi de aproximadamente $2 \mathrm{~m}$, de modo a facilitar a reprodutibilidade do ensaio. As áreas que apresentaram som cavo durante o ensaio foram mapeadas para compor o mapa de danos das fachadas. Este ensaio é utilizado de maneira complementar à inspeção visual e ao uso da termografia infravermelha.

\subsubsection{Termografia infravermelha}

A termografia infravermelha é uma técnica não destrutiva e sem contato para o diagnóstico de manifestações patológicas e identificação de estruturas ocultas (CORTIZO, 2007). Para Shepard (2007), o fluxo de calor pode ser parcial ou totalmente obstruído por superfícies que apresentem descontinuidades térmicas (por exemplo, paredes, limites de camadas ou defeitos), o que causa um aumento na temperatura superficial. A diferença de temperatura entre as superfícies sãs e as deterioradas, ou simplesmente a diferença de temperatura entre materiais diferentes, é captada pela câmera.

Para a geração dos termogramas utilizou-se câmera termográfica modelo FLIR T400, que capta a radiação infravermelha na resolução espectral de 7,5 $\mu \mathrm{m}$ até $13 \mu \mathrm{m}$ no infravermelho, sendo necessária a inserção de parâmetros em campos específicos do equipamento. Utilizou-se um termo-higrômetro digital, para determinação da temperatura e da umidade do ambiente. Foi medida a distância de obtenção das imagens, além de determinar a emissividade do alvo. As imagens geradas são representativas das temperaturas superficiais, demonstradas através de uma escala de cores. Na determinação da emissividade dos revestimentos foi aplicado o método da fita isolante, utilizado por Mario (2001). A emissividade obtida para o revestimento fulget foi de 0,85 ; para as pastilhas cerâmicas verdes foi de 0,86 ; para as pastilhas cerâmicas beges foi de 0,88 e para as pastilhas cerâmicas azuis de 0,90 .

\subsection{Caracterização do revestimento fulget}

Foram extraídas seis amostras, em três pontos da edificação, conforme indicado na figura 4 . A tabela 1 indica informações a respeito da orientação das fachadas, altura e profundidade de extração das amostras. Os locais de obtenção das amostras foram definidos com autorização do SPH e da Superintendência de Infraestrutura da universidade (SUINFRA).

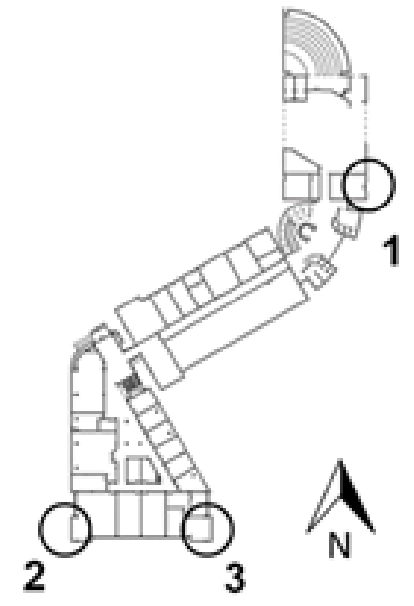

Figura 4: Pontos de extração de amostras de fulget para caracterização (fonte: ZINI et al., 2019)

Tabela 1 - Informações a respeito das amostras extraídas para caracterização do revestimento fulget

\begin{tabular}{c|c|c|c}
\hline Identificação & Orientação da fachada & Altura da extração & Profundidade da extração \\
\hline A1 & Leste & $1,30 \mathrm{~m}$ & $4,5 \mathrm{~cm}$ \\
\hline A2 & Oeste & $1,30 \mathrm{~m}$ & $3,0 \mathrm{~cm}$ \\
\hline A3 & Leste & $1,30 \mathrm{~m}$ & $4,0 \mathrm{~cm}$ \\
\hline
\end{tabular}

A composição da amostra A1 consistiu em duas camadas: fulget e emboço; as amostras A2 e A3 apresentaram, além dessas camadas, uma camada de chapisco. Isso pode estar relacionado à época de construção das partes da edificação. Conforme mencionado anteriormente, houve uma ampliação em sua área em 1999: as amostras A2 e A3 correspondem justamente à área de ampliação, enquanto a amostra A1 faz parte da construção original do Anexo I. 


\subsubsection{Reconstituição de traço}

Para a realização da reconstituição de traço das amostras do revestimento fulget, assim como do emboço e chapisco subjacentes, foi utilizada a metodologia proposta por Teutonico (1998), aplicada tradicionalmente pelo International Centre for the Study of the Preservation and Restoration of Cultural Property (ICCROM). Guerra (2019) também aplicou essa metodologia para caracterizar o revestimento de argamassa da edificação histórica "Casa Godoy", localizada em Porto Alegre. O método consiste, de forma resumida, na desagregação das amostras, com cuidados para não quebrar os grãos dos agregados, seguida de secagem em estufa a $75 \pm 5^{\circ} \mathrm{C}$ e imersão em solução de ácido clorídrico (1:4, $\mathrm{HCl} 37 \%$ :água deionizada). As amostras foram filtradas em um papel filtro qualitativo e, novamente, foi feita a secagem em estufa. A proporção de ligante:agregado foi determinada conhecendo-se a massa inicial da amostra desagregada, a massa dos agregados e dos finos retidos; a porcentagem dos finos retidos foi considerada como ligante.

Após a reconstituição de traço, foi determinada a distribuição granulométrica dos agregados. O procedimento foi realizado com utilização de peneiramento mecânico e seguindo as diretrizes da NBR NM 248:2003. Os agregados foram, ainda, observados em lupa estereoscópica do modelo ZEISS Stemi 508doc, com aumento máximo de 100x.

\subsubsection{Teste qualitativo de sais solúveis}

A verificação qualitativa da presença de sais solúveis também foi realizada de acordo com as recomendações de Teutonico (1998), com algumas adaptações sugeridas pelo Núcleo de Tecnologia da Preservação e da Restauração (NTPR), da Universidade Federal da Bahia (UFBA), conforme descrito por Sanjad (2002). O método de teste consistiu basicamente na desagregação das amostras e adição de água deionizada, sendo misturada e em seguida filtrada em papel filtro qualitativo. À uma alíquota do filtrado, foi aplicado $1 \%$ de difenilamina em ácido sulfúrico $\left(\mathrm{H}_{2} \mathrm{SO}_{4}\right)$ e a mudança para coloração azul é indicativa da formação de nitratos; em outra alíquota da amostra do filtrado foram aplicados os reagentes ácido nítrico $\left(\mathrm{HNO}_{3}\right)$ e nitrato de prata $\left(\mathrm{AgNO}_{3}\right)$, sendo a turvação da solução indicativa da formação de cloreto de prata $(\mathrm{AgCl})$ e, por fim, foram aplicados os reagentes $\mathrm{HCl}$ e solução de $5 \%$ de cloreto de bário $\left(\mathrm{BaCl}_{2}\right) \mathrm{em}$ água deionizada, sendo a ocorrência de turvação indicativa da formação de sulfatos $\left(\mathrm{BaSO}_{4}\right)$.

\section{RESULTADOS E DISCUSSÕES}

A partir da realização dos ensaios in loco e laboratoriais foram feitas as análises e discussões apresentadas a seguir, resultando no diagnóstico das manifestações patológicas presentes no revestimento das fachadas do Anexo I do Campus da Saúde, incluindo mapa de danos e termografia e na caracterização do emboço e chapisco subjacentes ao revestimento fulget

\subsection{Mapa de danos}

Os mapas de danos foram elaborados a partir da realização da inspeção visual e do ensaio de percussão com a finalidade de indicar o tipo de manifestação patológica, a localição, bem como sua dimensão no revestimento das fachadas analisadas. Os mapas de danos desenvolvidos para o trabalho da disciplina de Patologia das Edificações estão disponíveis de forma completa em ZINI et al. (2019).

Para este artigo, escolheu-se representar apenas o mapa de danos referente à fachada sul do Anexo I, figura 5, tendo em vista que é a fachada com menor incidência solar na cidade de Porto Alegre, no inverno, considerada, portanto, a condição mais crítica. Ademais, juntamente ao mapa de danos são indicadas manifestações patológicas através de fotografias registradas in loco, contemplando áreas do revestimento fulget e cerâmico, de forma a indicar as diferentes manifestações presentes em virtude do tipo de revestimento. De maneira complementar, foi utilizada a termografia infravermelha para confirmar as áreas de degradação. Os resultados mais detalhados da termografia serão apresentados no item 3.2. 


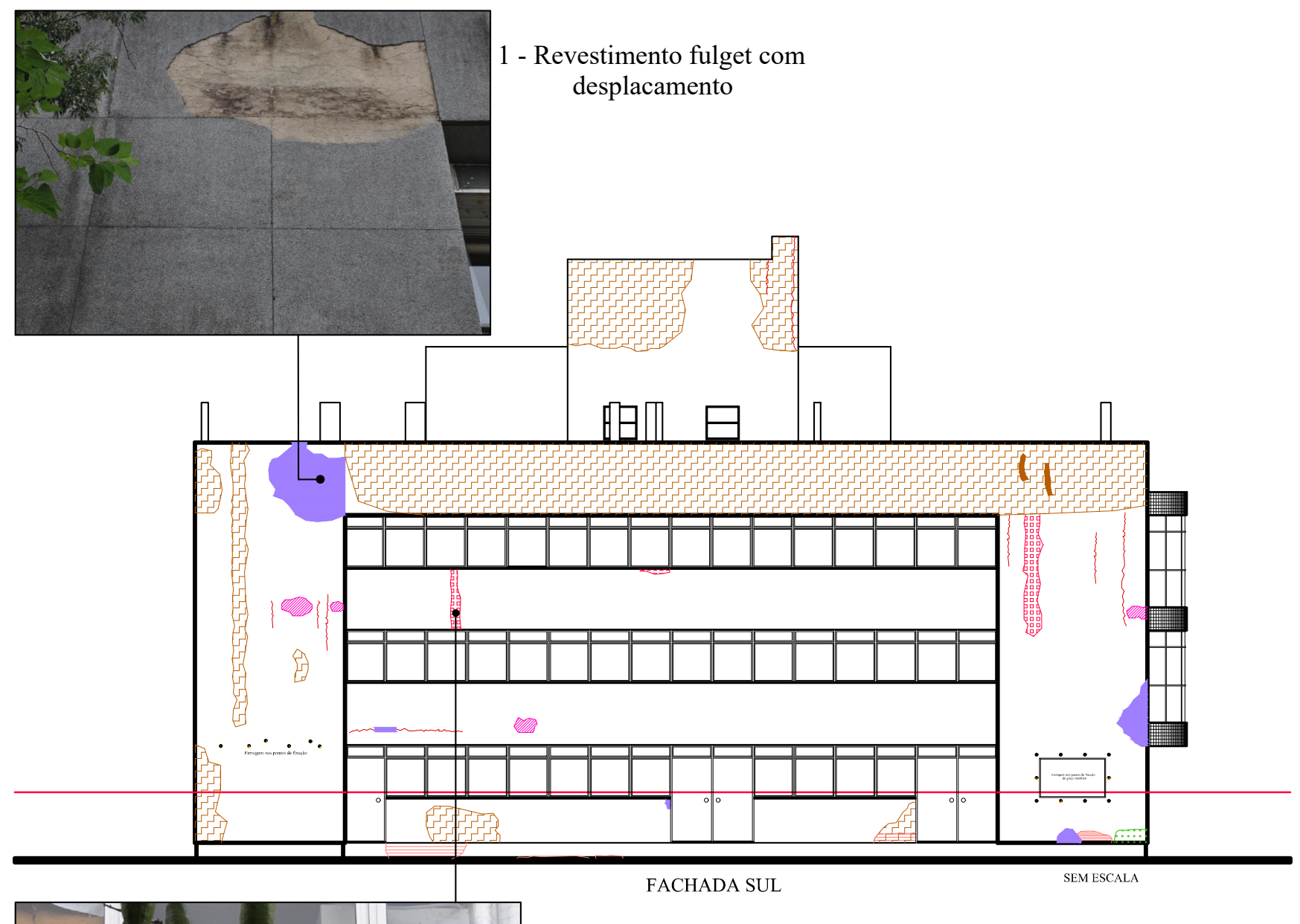

2- Revestimento cerâmico com biodeterioração - manchamento

LEVANTAMENTO VISUAL E MAPEAMENTO DE DANOS

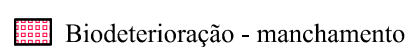

Descolamento (aderido) - com ou sem possível desplacamento imediato

$\square$ Desplacamento

$\boxminus$ Fissuras

Fianchamento por Sujidade

Manchamento por Umidade

$\square$ Manchamento corrosão

Percussão

$\boxminus$ Altura limite de execução do ensaio

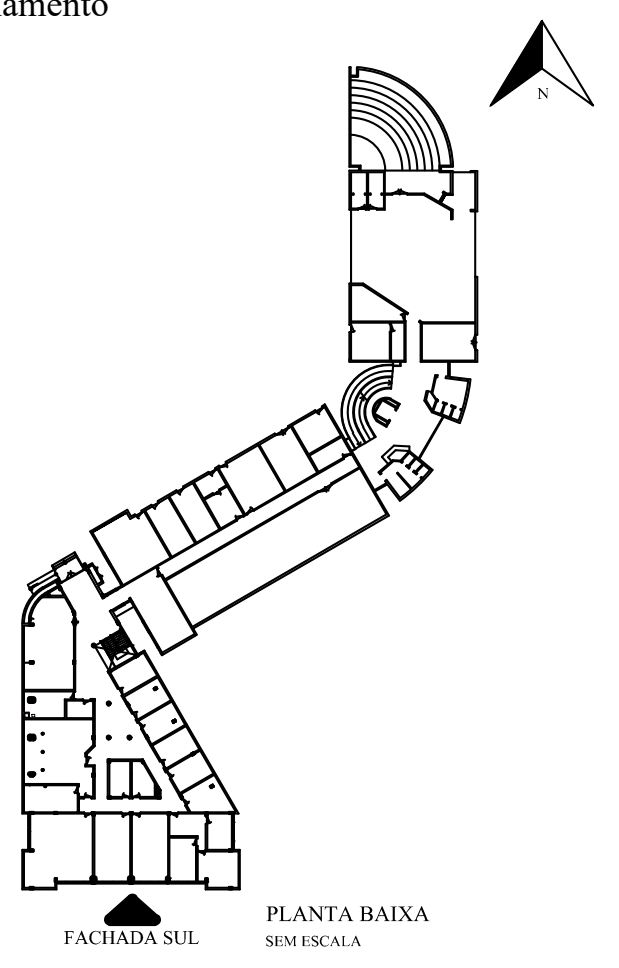

Figura 5 - Mapa de danos referente à fachada sul (fonte: adaptado de ZINI et al., 2019) 


\subsection{Termografia infravermelha}

Além de complementar as informações coletadas através da inspeção visual e do ensaio de percussão, a termografia apresentou-se como um método que permitiu estabelecer relações de causa e efeito entre as manifestações patológicas identificadas e suas possíveis fontes. Os contrastes de temperaturas são utilizados para fundamentar a explicação dos fenômenos, sendo as temperaturas mais quentes relacionadas às cores avermelhadas e as temperaturas mais frias relacionadas às cores azuladas. Na sequência, estão exemplificadas duas situações de uso da termografia na identificação de manifestações patológicas e investigação das suas possíveis causas.

A figura 6 (a) indica a localização na edificação das figuras 6 (b) e 6 (c). Os manchamentos observados na parte superior da platibanda podem ser causados por sujidades e biodeterioração. Também podem ser observadas na figura 6 (c) diferenças de temperaturas entre a parte superior e a inferior da platibanda, que podem provocar movimentações diferenciais entre elementos estruturais, de vedação e de revestimento. A temperatura elevada na platibanda pode ser explicada pela orientação oeste da fachada, fazendo com que esta receba maior insolação no período da tarde (momento em que foram capturadas as imagens). A combinação da temperatura adequada, com elevados valores de umidade relativa na fachada, apresenta-se como um parâmetro importante para o desenvolvimento dos microrganismos e demais agentes biológicos (VIITANEN et al., 2009).

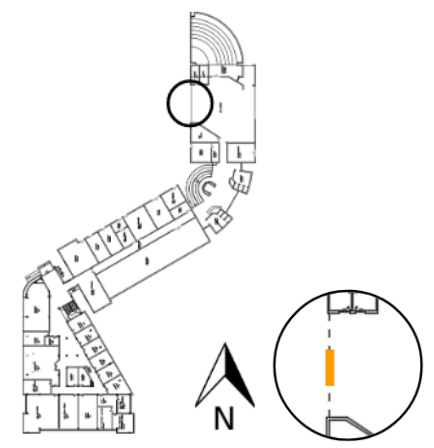

(a)

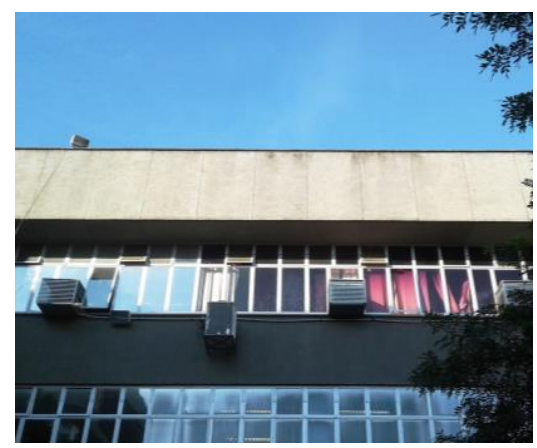

(b)

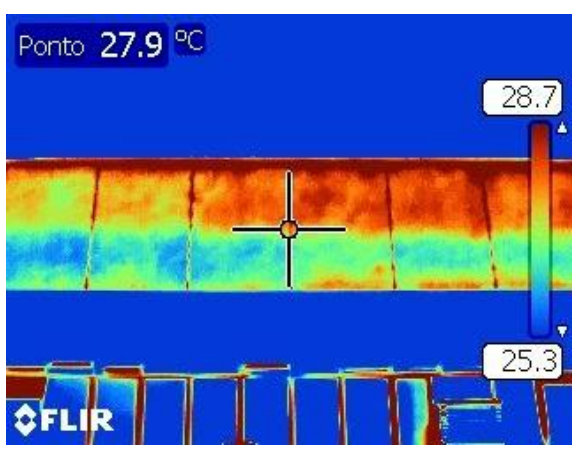

(c)

Figura 6: (a) Localização das figuras 6 (b) e 6 (c) na edificação; (b) Imagem digital referente à região em análise; (c) Imagem obtida em câmera termográfica da região em análise (fonte: ZINI et al., 2019)

A figura 7 (a) indica a localização na edificação das figuras 7 (b) e 7 (c). Pode ser observado na figura 7 (b) a ocorrência de um desplacamento na área revestida em fulget da platibanda. Também, é observado através da termografia uma região com temperaturas elevadas (próximas de $46,5^{\circ} \mathrm{C}$ ) em relação às demais áreas do revestimento da platibanda (figura 7 (c)). Esta área de temperaturas elevadas apresenta um visível descolamento do revestimento, representando um risco aos usuários da edificação e transeuntes. Analogamente à fachada apresentada na figura 6, as temperaturas elevadas podem ser justificadas pela orientação noroeste da fachada. $\mathrm{O}$ descolamento ocorreu na região da junta de movimentação entre duas placas de fulget, e pode ter sido causado pelo acúmulo de tensões nas bordas das placas devido a movimentações térmicas diferenciais.

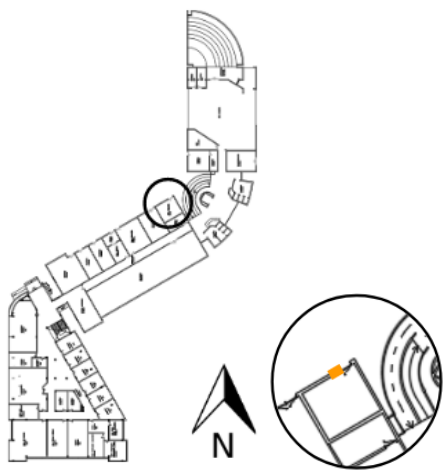

(a)

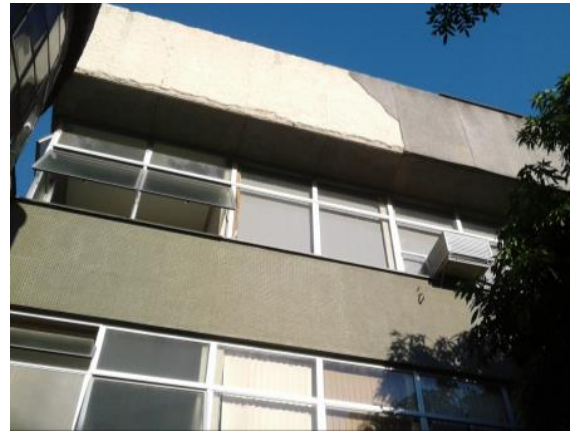

(b)

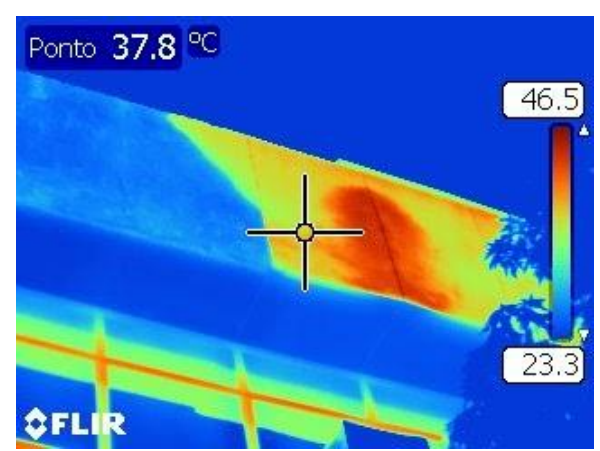

(c)

Figura 7: (a) Localização das figuras 7 (b) e 7 (c) na edificação; (b) Imagem digital referente à região em análise; (c) Imagem obtida em câmera termográfica da região em análise (fonte: ZINI et al., 2019) 


\subsection{Caracterização do revestimento fulget}

Neste item, o traço identificado para o emboço e o chapisco subjacentes ao revestimento fulget e a identificação qualitativa da presença dos sais solúveis são apresentados. Além disso, são apresentadas a distribuição granulométrica e análise em lupa dos agregados. Quanto à camada de fulget em si, não foi possível obter o proporcionamento correto de seu traço. Isso pode ser devido à origem possivelmente calcária do agregado graúdo, e, portanto, à sua constituição de carbonato de cálcio $\left(\mathrm{CaCO}_{3}\right)$, que dissolve durante a imersão na solução de $\mathrm{HCl}$. Desta maneira, a metodologia utilizada pode ter sido inadequada para a reconstituição do traço das camadas de fulget.

\subsubsection{Reconstituição de traço}

A tabela 2 apresenta os resultados de reconstituição de traço para as 3 amostras. As siglas A1 - E, A2 - E e A3 - E representam, respectivamente, as camadas de emboço das amostras 1,2 e 3 e as siglas A2 - C e A3 - C, o chapisco. Não estão apresentados na tabela 2 os resultados encontrados para a camada do fulget propriamente dito, já que o método foi considerado inadequado para o seu proporcionamento.

Tabela 2 - Reconstituição de traço (fonte: ZINI et al., 2019)

\begin{tabular}{c|c|c|c|c|c}
\hline Identificação & $\begin{array}{c}\text { Massa Total Seca } \\
(\mathrm{g})\end{array}$ & $\begin{array}{c}\text { Massa Agregados Secos } \\
(\mathrm{g})\end{array}$ & $\begin{array}{c}\text { Massa Finos Secos } \\
(\mathrm{g})\end{array}$ & $\begin{array}{c}\text { Massa Ligante } \\
(\mathrm{g})\end{array}$ & $\begin{array}{c}\text { Traço em } \\
\text { Massa }\end{array}$ \\
\hline $\mathrm{A} 1$ - E & 45,85 & 35,77 & 2,03 & 8,05 & $1: 3,55$ \\
\hline $\mathrm{A} 2-\mathrm{E}$ & 49,04 & 32,36 & 7,68 & 9,00 & $1: 1,94$ \\
\hline $\mathrm{A} 2-\mathrm{C}$ & 20,89 & 14,32 & 3,01 & 3,56 & $1: 2,18$ \\
\hline $\mathrm{A} 2-\mathrm{E}$ & 30,75 & 18,90 & 3,97 & 7,88 & $1: 1,59$ \\
\hline $\mathrm{A} 2-\mathrm{C}$ & 14,62 & 10,03 & 1,59 & 3,00 & $1: 2,19$ \\
\hline
\end{tabular}

Em relação às camadas de chapisco e emboço, observa-se que os traços apresentaram teores baixos de ligante. Na tabela 3 são apresentados os resultados de dimensão máxima e módulo de finura dos agregados. A figura 8 ilustra as curvas granulométricas obtidas para as amostras A1, A2 e A3, respectivamente.

Tabela 3 - Dimensão máxima e módulo de finura dos agregados (fonte: adaptado de ZINI et al., 2019)

\begin{tabular}{c|c|c}
\hline Amostra & Dimensão Máxima & Módulo de finura \\
\hline A1 - C & 2,40 & 2,30 \\
\hline A2 - E & 2,80 & 1,53 \\
\hline A2 - C & 2,80 & 2,24 \\
\hline A3 - E & 0,60 & 0,76 \\
\hline A3 - C & 1,20 & 1,48 \\
\hline
\end{tabular}

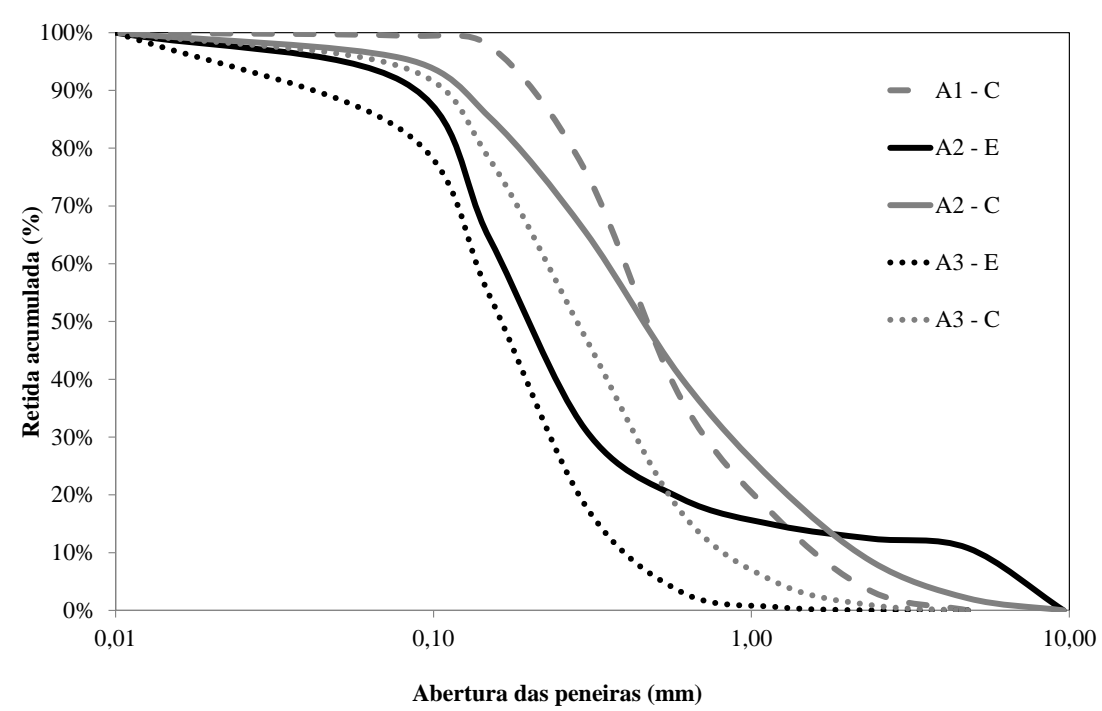

Figura 8 - Curvas granulométricas A1, camada de chapisco A2, camadas de emboço e chapisco e A3, camadas de emboço e chapisco (fonte: adaptado de ZINI, 2019) 
Em geral, é possível observar que os agregados das camadas de chapisco apresentam partículas mais grossas e, assim, um maior módulo de finura do que os agregados da camada de emboço. Isso pode estar relacionado à rugosidade requerida para esta camada.

Na figura 9 são apresentadas as imagens obtidas em lupa estereoscópica para as camadas da A3. É possível observar que os agregados das diferentes camadas apresentam coloração e formato semelhantes; isso também aconteceu entre as diferentes amostras. Nota-se que os agregados das camadas de chapisco apresentam maiores dimensões que os do emboço, como foi anteriormente apresentado para o ensaio de granulometria. Destaca-se que os agregados superiores a 4,8 mm da camada de fulget efetivamente se dissolveram na imersão em solução de $\mathrm{HCl}$, como sugerido anteriormente, uma vez que não é possível observá-los nas microfotografias.

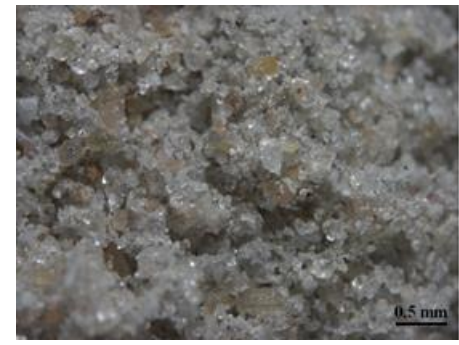

(a)

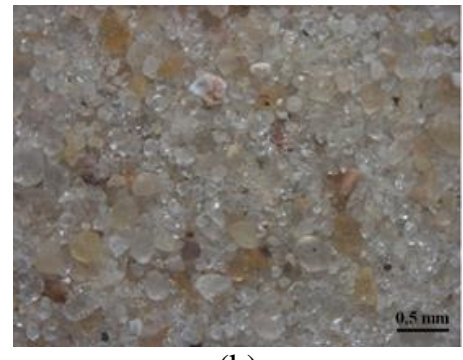

(b)

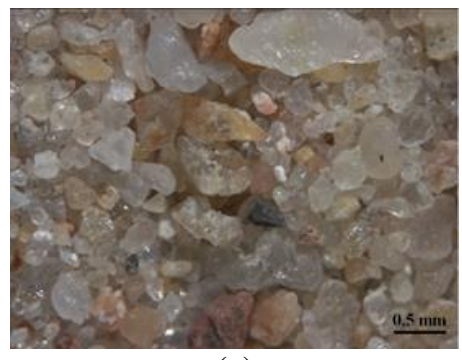

(c)

Figura 9 - Observação em lupa estereoscópica dos agregados após a reconstituição de traço: (a) A3 - Fulget; (b) A3 - E; (C) A3 - C (fonte: ZINI et al., 2019).

\subsubsection{Teste qualitativo de sais solúveis}

Os resultados do teste qualitativo de sais solúveis estão apresentados na tabela 4 . Neste trabalho foi utilizada a classificação sugerida pelo NTPR (UFBA) É interessante observar que somente a amostra A1, correspondente à constituição original da edificação, antes das obras de ampliação, foi a única que não apresentou sais solúveis em nenhuma de suas camadas.

Tabela 4 - Teste qualitativo de sais solúveis (fonte: ZINI et al., 2019)

\begin{tabular}{c|c|c|c}
\hline Amostra & Sulfatos & Cloretos & Nitratos \\
\hline A1 - F & - & - & - \\
\hline A1 - C & - & - & - \\
\hline A2 - F & ++ & +++ & - \\
\hline A2 - E & +++ & +++ & - \\
\hline A2 - C & - & - & - \\
\hline A3 - F & - & + & - \\
\hline A3 - E & ++ & - & - \\
\hline A3 - C & + & - & média quantidade; +++ grande quantidade. \\
\hline
\end{tabular}

Além disso, em nenhuma das amostras (A1, A2 e A3) foi identificada a presença de nitratos. Segundo Guterres (2009), os nitratos podem ser provenientes do solo contaminado ou adubado. Desta forma, é possível inferir que, possivelmente, o solo da área não apresenta nitratos em quantidade suficiente para migrar e contaminar o revestimento da fachada.

Em relação aos cloretos, foi observada uma pequena quantidade na amostra A3 - F e elevadas quantidades nas amostras A2 - F e A2 - E. O cloreto pode ser proveniente do $\mathrm{HCl}$, por vezes utilizado na produção das placas de fulget para a dissolução parcial do ligante e fornecimento do aspecto estético de agregados aparentes.

Por fim, em relação aos sulfatos, observa-se a presença em pequena quantidade na amostra A3 - C, em quantidade moderada nas camadas A2 - F e A3 - C e em elevada quantidade na amostra A2 - E. Os tijolos, a água de amassamento e a reação entre tijolo, cimento e agregados são possíveis fontes de sulfatos. 


\section{CONSIDERAÇÕES FINAIS}

O levantamento visual e o mapeamento de danos desenvolvidos neste trabalho possibilitaram a identificação das manifestações patológicas presentes nos revestimentos fulget e em pastilhas cerâmicas das fachadas da edificação conhecida como Anexo I do Campus da Saúde da UFRGS. Esses danos podem estar relacionados a processos diversos de degradação, envolvendo os próprios materiais componentes dos revestimentos e suas características, mas também às condições do entorno e de utilização da edificação.

Foram encontrados manchamentos por sujidade, biodeterioração, umidade e corrosão, além de desplacamentos, fissuras e descolamentos com ou sem possível desplacamento imediato. O ensaio de percussão e a obtenção de imagens com a câmera termográfica permitiram a identificação de diversos pontos em que o revestimento, apesar de ainda preso à parede, já apresenta sua aderência prejudicada. Especialmente nas regiões mais altas da edificação, a técnica da termografia possibilitou a percepção de diversas regiões descoladas, especialmente constituídas de fulget, representando risco aos usuários.

Quanto à caracterização do revestimento fulget e das camadas subjacentes, verificou-se que no ensaio de reconstituição de traço, os agregados característicos da camada externa do fulget foram decompostos pelo $\mathrm{HCl}$ e, dessa forma, a determinação de sua distribuição granulométrica ficou prejudicada. Ainda, identificou-se que os agregados do chapisco apresentam dimensões superiores à do emboço. Além disso, em geral, os agregados encontrados nas diferentes camadas e amostras constituem-se de colorações e formatos similares entre si. Foram identificados qualitativamente sais solúveis nas amostras correspondentes à área de ampliação da edificação. Observou-se a presença de sulfatos e cloretos, com maior intensidade nas amostras A2 - F e A2 - E e A3 - E.

Este artigo, baseado no trabalho desenvolvido na disciplina de Patologia das Edificações do PPGCI (ZINI et al., 2019), atendeu seu objetivo de efetuar o diagnóstico do revestimento das fachadas do Anexo I e a caracterização de seu revestimentofulget, contribuindo para a conservação de um dos prédios da UFRGS, de forma a buscar uma utilização com segurança para os usuários e a sociedade, além de preservar sua importante função como espaço público e educacional.

\section{AGRADECIMENTOS}

Os autores agradecem ao suporte financeiro do CNPq (Conselho Nacional de Desenvolvimento Científico e Tecnológico) e da CAPES (Coordenação de Aperfeiçoamento de Pessoal de Nível Superior), ao SPH (Setor de Patrimônio Histórico) e à SUINFRA (Superintendência de Infraestrutura) da UFRGS (Universidade Federal do Rio Grande do Sul), ao LAMTAC (Laboratório de Materiais e Tecnologia do Ambiente Construído), ao PPGCI (Programa de Pós-Graduação em Engenharia Civil: Construção e Infraestrutura) e à UFRGS. Acho que podemos agradecer também à CAPES e CNPQ, fonte de recurso das nossas bolsas.

\section{REFERÊNCIAS}

ASSOCIAÇÃO BRASILEIRA DE NORMAS TÉCNICAS. NBR NM 248: Agregados - Determinação da composição granulométrica. Rio de Janeiro, 2003.

. NBR 15575-4 - Edificações habitacionais - Desempenho - Parte 4: Requisitos para os sistemas de vedações verticais internas e externas - SVVIE. Rio de janeiro, 2013.

CORTIZO, E. C. Avaliação da técnica de termografia infravermelha para identificação de estruturas ocultas e diagnóstico de anomalias em edificações: ênfase em edificações do patrimônio histórico. 2007. 177 f. Tese - Escola de Engenharia da Universidade Federal de Minas Gerais, Departamento de Engenharia Mecânica. Belo Horizonte, MG, Brasil, 2007.

FLORES-COLEN, I.; BRITO, J. Building façades maintenance support system. In: World Congress on Housing Construction, An Interdisciplinary Task. Coimbra: 2002.

GONÇAlveS, A.; BRITO, J.; AMARO, B. Systematic Approach to Inspect, Diagnose, and Repair Masonry Walls. Journal of Performance of Constructed Facilities, v. 29, 2014.

GUERRA, F. L.; LOPES, W.; CAZAROLLI, J. C.; LOBATO, M.; MASUERO, A. B.; DAL MOLIN, D. C. C.;

BENTO, F. M.; SCHRANK, A.; VAINSTEIN, M. H. Biodeterioration of mortar coating in historical buildings: Microclimatic characterization, material, and fungal community. Building and Environment, v. 155, p. 195-209, 2019. 
IFRS - INSTITUTO FEDERAL DO RIO GRANDE DO SUL. Institucional - sobre o Campus Porto Alegre. Disponível em: <http://www.poa.ifrs.edu.br/index.php?option=com_content\&view=article\&id=273\&Itemid=320>. Acesso em: 17 dez. 2019.

GUTERRES, P. R. C. Argamassas de reabilitação: estudo da sua utilização e do seu comportamento para o tratamento e recuperação de construções afetadas por eflorescências. 2009. 265f. Tese - Universidade Federal do Rio de Janeiro e Laboratório Nacional de Engenharia Civil. [s.1.]: 2009.

KLEBER, D. H. Análise do desempenho de sistema de vedação vertical externo com diferentes tipos de argamassa, através de simulação higrotérmica para a cidade de Porto Alegre. 2018. 34 f. Trabalho de Diplomação (Graduação em Engenharia Civil) - Escola de Engenharia da Universidade Federal do Rio Grande do Sul, Departamento de Engenharia Civil. Porto Alegre, RS, Brasil, 2018.

MADUREIRA, S; FLORES-COLEN, I; BRITO, J.; PEREIRA, C. Maintenance planning of facades in current buildings. Construction and Building Materials, v. 147, p. 790-802, 2017.

MARIO, M. Uso da termografia como ferramenta não destrutiva para avaliação de manifestações patológicas ocultas. 2011. 68f. Trabalho de Diplomação (Graduação em Engenharia Civil) - Escola de Engenharia da Universidade Federal do Rio Grande do Sul, Departamento de Engenharia Civil. Porto Alegre, RS, Brasil, 2011.

MASCARÓ, L. R. Energia na edificação - estratégia para minimizar seu consumo. 2 ed. São Paulo: Projeto, 1991.

SANJAD, T. A. B. C. Patologias e conservação de azulejos: um estudo tecnológico de conservação e restauração de azulejos, dos séculos XVI, XVII e XIX, encontrados nas cidades de Belém e Salvador. 2002. 206f. Dissertação Faculdade de Arquitetura da Universidade Federal da Bahia. Salvador, BA, Brasil, 2002.

SILVA, A. C.; GIRALT, R. P. Estabelecimento de um índice de chuva dirigida para Porto Alegre. In: Encontro Nacional de Tecnologia do Ambiente Construído - Tecnologia e Qualidade na Habitação. Rio de Janeiro: Antac, p. 605610, 1995.

SILVA, M. N. B. Avaliação Quantitativa da Degradação e Vida Útil de Revestimentos de Fachada - Aplicação ao Caso de Brasília/DF. 2014. 297 p. Tese - Faculdade de Tecnologia da Universidade de Brasília, Departamento de Engenharia Civil e Ambiental. Brasília, DF, Brasil, 2014.

SHEPARD, S. M. Thermography of composites. Materials Evaluation, v. 65, p. 690-696. 2007.

TEUTONICO, J. M. A Laboratory Manual for Architectural Conservators. Roma: 1988.

VIITANEN, H.; VINHA, J.; SALMINEN, K.; OJANEN, T.; PEUHKURI, R.; PAAJANEN, L.; LÄHDESMÄKI, K. Moisture and Bio-deterioration Risk of Building Materials and Structures. Journal of Building Physics. v. 33, n. 3, p. 201-224, 2009. Disponível em: <https://journals.sagepub.com/doi/pdf/10.1177/1744259109343511>. Acesso em: 09 jul. 2019.

WREGE, M. S.; STEINMETZ, S.; REISSER JÚNIOR, C.; ALMEIDA, I. R. Atlas climático da região sul do Brasil estados do Paraná, Santa Catarina e Rio Grande do Sul. 2 ed: Embrapa, 2012.

ZINI, A.; DALAZEN, C. D. A.; MASUERO, G. B.; BERSCH, J. D.; ANDRADE NETO, J. S.; KIRCHNER, L. S.; PY, L. G.; BIANCHETTI, L. G. M.; MAZZUCO, M.; DESSUY, T. Y.; SILVA, T. S. M.; PASINATTO, V. Diagnóstico das manifestações patológicas das fachadas do prédio Anexo I - Campus Saúde - UFRGS e proposta de intervenção. 2019. 127 f. Relatório técnico. Escola de Engenharia da Universidade Federal do Rio Grande do Sul, Programa de Pós-Graduação em Engenharia Civil: Construção e Infraestrutura. Porto Alegre, RS, Brasil, 2019. 